\title{
Bullying di Tempat Kerja di Indonesia
}

\author{
Ika Adita Silviandari ${ }^{1}, \mathcal{E}$ Avin Fadilla Helmi ${ }^{2}$ \\ ${ }^{1}$ Fakultas Psikologi Universitas Brawijaya \\ ${ }^{2}$ Fakultas Psikologi Universitas Gadjah Mada
}

\begin{abstract}
Workplace bullying is one of organizational phenomenon that has received a lot of attention from many parties, both academics and practitioners. The workplace bullying is like an iceberg phenomenon. It is exist but hard to be revealed and lifted to the surface. This phenomenon can be seen as practically and methodologically point of view. Practically, it is caused by passivity and silent act from the victim or bullying eyewitnesses, and methodologically, it hasn't found the standard concept of workplace bullying which causing lack of workplace bullying research. In this article, the author try to review the workplace bullying's concepts and constructs, starting by reviewing the problem of definition, including type, frequency, \& duration of bullying actions, and considering the role of workplace cultural values and norms in influencing the perception of bullying behavior.
\end{abstract}

Keywords: concept; constructs; workplace bullying

\section{Pengantar}

Kekerasan di tempat kerja merupakan salah satu fenomena organisasi yang banyak mendapatkan perhatian dari berbagai kalangan, baik dari peneliti, pendidik, organisasi perlindungan, maupun tokoh masyarakat (Rudi, 2010). Hal ini dikarenakan kekerasan di tempat kerja dapat memberikan konsekuensi dalam berbagai lini, mulai dari individu, kelompok, organisasi, sampai dengan lingkungan sosial secara luas. Bagi individu, kekerasan di tempat kerja memberikan konsekuensi yang dapat merusak kesehatan dan kesejahteraan karyawan. Bagi kelompok, kekerasan di tempat kerja dapat memengaruhi efektivitas tim dan norma kelompok yang telah terbangun. Bagi organisasi, kekerasan di tempat kerja dapat memberikan dampak bagi kinerja organisasi dan

\footnotetext{
${ }^{1}$ Korespondensi artikel ini dapat dilakukan melalui: ika.adita.s@mail.ugm.ac.id; ªvinpsi@ugm.ac.id
}

juga budaya organisasi yang ada. Sedangkan bagi lingkungan sosial secara luas, adanya kekerasan di tempat kerja akan memunculkan masalah sosial baru terkait dengan konsekuensi hukum (Samnani \& singh, 2012). Kekerasan di tempat kerja ini sering diistilahkan dengan "bullying" di tempat kerja. Istilah ini dianggap lebih mewakili dan lebih lengkap dibandingkan dengan istilah-istilah lain yang sejenis untuk menggambarkan fenomena yang sama. Tidak jarang bullying disinonimkan dengan "harassment". Harassment sendiri berasal dari kata "to harass" yang berakar dari kata dalam Bahasa Perancis kuno "harer" yang artinya melakukan upaya penyerangan, dan juga memiliki akar kata dalam Bahasa Inggris kuno "hergian" yang artinya "to ravage" atau "despoil" (mengganggu, mengusik, merusak) (Hidayati dan Rahayuningsih, 2014). Pada Kamus Besar Bahasa Indonesia istilah bullying memiliki tiga padanan kata yaitu merundung 
(berasal dari kata rundung), merisak (berasal dari kata risak) dan menyakat (yang berasal dari kata sakat), yang artinya adalah mengganggu, mengusik terusmenerus, dan menyusahkan (KBBI, 2016). Pada artikel ini, penulis akan tetap menggunakan istilah "bullying", karena istilah ini dianggap lebih sesuai dan lebih mewakili kajian yang akan dibahas pada artikel ini.

Bullying di tempat kerja merupakan salah satu permasalahan organisasi yang masih sering terjadi hingga saat ini. Hal ini diperkuat dengan hasil survei yang telah dilakukan oleh Workplace Bullying Institute di Amerika pada tahun 2017 yang menunjukkan bahwa 19\% orang Amerika mengalami bullying di tempat kerja, 19\% lainnya telah menyaksikan adanya bullying di tempat kerja, dan $63 \%$ menyadari adanya bullying di tempat kerja (Workplace Bullying Institute, 2017). Salah satu organisasi atau perusahaan yang saat ini sedang concern untuk mengatasi adanya bullying di tempat kerja, adalah Google. Menurut laporan The Wall Street Journal, Google membuat peraturan baru dan mengatakan akan menindaklanjuti setiap karyawan yang melakukan bullying, diskriminasi, menyerang karyawan lainnya, atau terlibat dalam diskusi yang bisa menganggu produktivitas lingkungan kerja. Pedoman mengenai hal ini bertujuan menjaga lingkungan kerja Google terbebas dari segala bentuk saling ejek. Hal ini merupakan aturan pertama yang dikeluarkan Google untuk mengatur agar diskusi di dalam perusahaannya tetap terkendali (Salsabila, 2018).

Fenomena bullying tidak hanya terjadi di negara-negara maju saja, namun juga terjadi di negara berkembang seperti di Indonesia. Sebagaimana hasil penelitian yang telah dilakukan oleh Gunawan, Prihanto, \& Yuwanto (2009) mengenai kekerasan di tempat kerja (workplace bullying) terhadap 123 orang pekerja di Surabaya, diperoleh data bahwa $49 \%$ responden menjadi saksi mata terjadinya bullying di tempat kerja dan mengalami beberapa efek, yaitu 1) efek psikologis yang berupa rasa marah, terluka, sedih, kecewa, kehilangan rasa percaya diri, marah pada diri sendiri, merasa terisolasi, frustrasi di tempat kerja, dan mengalami ketakutan dalam menghadapi orang lain; 2) efek perilaku berupa sikap defensif, hilangnya komitmen kerja, dan dorongan untuk berhenti dari pekerjaan. Namun sayangnya, banyak di antara korban bullying yang bersikap pasif atau mendiamkan saja terjadinya bullying, sehingga hal ini dapat memberikan dampak yang negatif, salah satunya adalah potensi untuk terus menjadi korban bullying (Gunawan et al., 2009). Kondisi inilah yang pada akhirnya membuat fenomena bullying menjadi seperti fenomena gunung es (iceberg) yang sulit untuk diungkap dan diangkat ke permukaan.

Dalam artikel ini, penulis mencoba untuk meninjau konsep dan konstruksi bullying di tempat kerja, dimulai dengan meninjau masalah definisi, termasuk jenis, frekuensi, dan durasi tindakan bullying, dan mempertimbangkan peran nilai dan norma budaya tempat kerja dalam memengaruhi persepsi perilaku bullying.

\section{Pembahasan}

\section{Bullying dari Masa ke Masa}

Pada tahun 1960-an seorang doktor Swedia yaitu Dan Olweus mendeteksi jenis perilaku bermusuhan (hostile), khususnya dalam lingkungan sekolah yang terjadi dalam kurun waktu yang lama, perilaku ini disebut dengan mobbing atau bullying. Pada awal tahun 1980-an, Profesor Leymann menemukan perilaku bermusuhan dalam jangka panjang yang memiliki karakteristik 
yang sama dengan penelitian yang sebelumnya telah dilakukan oleh Dan Olweus. Namun fenomena yang diamati Leymann ini terjadi pada karyawan. Sejak saat itu Heinz Leymann menjadi pakar internasional yang paling terkenal dalam bidang bullying di tempat kerja (workplace bullying) (Einarsen, 2011).

Heinz Leymann dianggap sebagai peneliti pertama dan pelopor dalam penyebaran istilah bullying atau mobbing di Eropa. Perintis Eropa lainnya di bidang ini adalah psikiater Prancis Marie France Hirigoyen dan psikolog Spanyol Iñaki Piñuely Zabala. Leymann mempelopori penelitian tentang mobbing di tahun 1980-an. Penelitian di bidang ini awalnya didasarkan pada studi kasus tentang sejumlah perawat yang telah melakukan atau mencoba melakukan bunuh diri karena adanya suatu peristiwa di tempat kerja (wikipedia.org). Dalam buku pertamanya (tahun 1986) yang berjudul Vuxenmobbing - om psykiskt våld I arbetslivet atau yang dalam bahasa Inggris diartikan Adult Mobbing: on Mental Violence in Working Life, mobbing didefinisikan sebagai perilaku bermusuhan dan komunikasi yang tidak etis, yang diarahkan secara sistematis oleh satu atau beberapa individu terhadap satu individu yang lainnya. Mobbing membuat individu menjadi terdesak kepada posisi yang tidak berdaya dan lemah, di mana mereka kemudian ditahan pada posisi tersebut dan aktivitas intimidasi ini akan berlangsung dalam waktu yang cukup lama. Definisi Leymann ini lebih menekankan pada dampak perilaku yang lebih luas daripada tingkat keparahan dari perilaku mobbing tersebut. Definisi ini juga lebih difokuskan pada ketegangan psikologis individu daripada tindakan yang menjadi pemicu munculnya mobbing. Dia juga menekankan bahwa, dalam mendefinisikan mobbing harus diartikan secara jelas dan juga harus nampak perbedaannya dengan fenomena negatif lainnya (misalnya: rasisme, ketidaksetaraan gender, dan lain-lain), sehingga ketika akan mendefinisikan suatu perilaku apakah itu mobbing atau bukan maka harus diamati dengan sangat hati-hati dan jeli (Westhues, 2003).

Penelitian bullying di tempat kerja mengalami perkembangan yang sangat signifikan ketika European Journal of Work dan Organizational Psychology, mengesahkan bullying dan mobbing di tempat kerja menjadi sebuah kajian ilmiah yang perlu untuk dipelajari. Saat itu penelitian Stale Einarsen dan Hoel dari Skandinavia cukup mendominasi area tersebut. (www.workplacebullying.org/the-movemennt/).

Menurut WBI, adanya penelitian mengenai bullying di tempat kerja ini pada akhirnya melahirkan adanya gerakan anti bullying pada beberapa negara. Diantaranya adalah di Australia, pada tahun 1990-an membentuk Beyond Bullying Association dan menjadi tuan rumah konferensi pada tahun 1994 dan 2002. Tahun 2014 Undang-Undang (UU) anti bullying di lingkungan kerja efektif berlaku mulai 1 Januari 2014 sebagai bagian dari perubahan UU Keadilan Kerja yang diloloskan parlemen Australia pada Juni 2013 lalu.

Gerakan anti bullying di Afrika Selatan dimulai tahun 1997 dengan ditandai terbitnya buku: Hyenas at Work. Salah satu penulis buku tersebut yaitu Susan MaraisSteinman, memulai untuk mendirikan Workplace Dignity Institute di negaranya. Gerakan anti bullying di Perancis, dimulai pada tahun 1998-an ketika buku karya Marie France Hirigoyen mulai booming. Amerika, sebelum tahun 1998 jarang peneliti di bidang sosial yang berani untuk mengangkat bullying sebagai topik penelitian mereka. Peneliti Amerika yang produktif dalam bidang kajian bullying ini adalah Namie dan Pamela Lutgen-Sandvik. 
Namie mendirikan Workplace Bullying Institute.

\section{Apakah Pengertian Bullying di Tempat Kerja?}

Pada beberapa penelitian, istilah bullying banyak ditukar artinya dengan istilahistilah yang lainnya. Di negara-negara berbahasa Inggris seperti Australia, di negara-negara Eropa Utara (Einarsen 1996; Vartia 1996; Salin 2001) dan di Turki (Timucin, Yildirim, \& Yildirim, 2007) istilah yang sering digunakan adalah bullying. Di negara-negara berbahasa Jerman dan Belanda, peneliti lebih menyukai untuk menggunakan istilah mobbing (Zapf, 1999). Sedangkan pada beberapa literatur yang ada di Amerika Utara, untuk menggambarkan fenomena perundungan, peneliti menggunakan berbagai konsep seperti: workplace aggression ( O'Leary-Kelly, Griffin, \& Glew, 1996); victimization (Aquino, Grover, Bradfield, \& Allen, 1999); interpersonal deviance (Bennet \& Robinson, 2003); workplace mobbing (Duffy \& Sperry, 2007); workplace incivility (Andersson \& Pearson, 1999). Selain itu terdapat beberapa istilah lain yang sering digunakan untuk menggambarkan fenomena perundungan, yaitu harassment (Brodsky 1976); scapegoating (Thylefors, 1987); workplace trauma (Wilson 1991); work harassment (Bjorkqvist, Osterman, \& Hielt-Back, 1994); abusive behaviour/emotional abuse (Keashly, Trott, \& MacLean, 1994); non-sexual harassment (Zapf \& Einarsen 2001), psychological harassment (Vartia 1996).

Bullying secara umum didefinisikan sebagai bagian dari perilaku agresif, yang dilakukan secara berulang, dan terdapat ketidakseimbangan kekuasaan sehingga sulit bagi korban untuk membela dirinya. Menurut Einarsen (2000), bullying merupakan situasi di mana seseorang berulang kali dan selama periode waktu tertentu terpapar tindakan negatif, yaitu adanya tindakan kekerasan yang terus menerus, komentar ofensif atau menggoda, cemoohan atau pengecualian sosial yang dilakukan oleh rekan kerja, pengawas atau bawahan. Sedangkan Namie (2003) mendefinisikan bullying di tempat kerja sebagai permusuhan antar pribadi yang disengaja, diulang dan pada tingkat yang dapat membahayakan kesehatan maupun status ekonomi dari individu yang ditargetkan. Lebih jauh lagi, Namie menjelaskan bahwa hal tersebut didorong oleh kebutuhan para pelaku untuk mengendalikan orang lain. Peneliti Amerika yang lain, yaitu Neuman dan Baron (1998) memaparkan perundungan di tempat kerja sebagai tindakan agresi interpersonal yang artinya adalah segala bentuk perilaku yang ditujukan untuk melukai atau menyakiti orang lain.

Apabila merujuk pada penelitian-penelitian yang telah ada saat ini, tampak bahwa konseptualisasi bullying di tempat kerja memiliki variasi yang cukup tinggi di berbagai negara. Variasi dalam mengkonseptualisasikan bullying di tempat kerja tidak terlepas dari adanya framework sosialbudaya dan hubungan industrial yang berbeda antar organisasi. Meski demikian terdapat tiga ciri utama pembeda perilaku disebut sebagai bullying, yaitu: pertama, perilaku yang bersifat menetap atau persisten (Einarsen, Hoel, Zapf, \& Cooper, 2003) artinya bentuk perilaku tersebut yang berulang, dalam jangka waktu tertentu, dan perilaku yang berpola. Kedua, adanya kesenjangan pengaruh (imbalance power). Menurut Lutgen-Sandvik (2005) bullying ditandai dengan adanya dua kekuatan (power) yang tidak seimbang antara pelaku dan target perundungan. Hal lain yang juga termasuk ke dalam kesenjangan pengaruh adalah adanya penggunaan kekuatan yang tidak sah atau tidak sesuai yang berasal dari struktur kekuatan formal organisasi untuk melanggar atau mengganggu batas perilaku 
yang sesuai di tempat kerja (Branch, Ramsay, \& Barker; 2013; Hutchinson, Wilkes, Jackson, \& Vickers, 2010). Ketiga, adanya kebencian, rasa tidak suka, dan tindakan bermusuhan. Adanya intensionalitas tindakan negatif yang dimanifestasikan dalam bentuk perilaku yang sistematis dan disengaja (Leymann, 1990; Einarsen, Hoel, Zapf dan Cooper, 2011; Zapf dan Einarsen, 2001).

Bentuk perilaku bullying bergerak mulai dari perilaku yang bersifat implisit hingga eksplisit dan dapat diidentifikasi (Parzefall dan Salin, 2010; dan Stouten, Baillien, Van den Broeck, Camps, De Witte dan Euwema, 2010). Perilaku tersebut telah dibedakan menjadi tiga aspek yaitu: pertama, bullying yang berkaitan dengan individu. Bullying pada aspek ini merupakan bentuk bullying yang ditujukan untuk menyerang kehidupan pribadi. Aspek ini meliputi isolasi sosial, kritik berulang dan terus menerus, agresi verbal, penghinaan dalam menyebarkan rumor atau gosip, dan menggoda.

Kedua, bullying yang berkaitan dengan pekerjaan. Bullying pada aspek ini meliputi perilaku yang ditujukan untuk menyerang kehidupan individu yang berkaitan dengan pekerjaan, yang biasanya ditandai dengan memanipulasi informasi dan kontrol pekerjaan yaitu memberikan tenggang waktu pekerjaan yang tidak masuk akal, mengurangi atau menghilangkan tanggung jawab, pengawasan berlebih terhadap pekerjaan, memberikan beban kerja berlebih, dan menyembunyikan informasi.

Ketiga, intimidasi. Pada aspek ini menunjukkan bentuk perilaku bullying yang biasanya melibatkan kontak fisik maupun psikis seperti, menggebrak meja, menggertak, mendorong dan perilaku lain yang dapat mengancam dan membahayakan korban.

\section{Bullying dan Budaya}

Literatur bullying yang ada masih kurang mempertimbangkan atau memperhatikan adanya realitas budaya (Sidle, 2010; Jennifer, Restubog dan Zagenczyk, 2010). Bullying adalah fenomena yang dibangun secara sosial (Lewis, 2003) dan skema kognitif dan mekanisme motivasi yang diwakili dalam orientasi budaya seseorang untuk membentuk persepsi dan reaksi terhadap bullying (Agarwal dan Gupta, 2016). Hasil penelitian Power et al. (2013) menunjukkan bahwa terdapat tiga orientasi yang menunjukkan bahwa budaya yang berbeda memiliki tingkat penerimaan yang berbeda terhadap bullying di tempat kerja. Adapun tiga orientasi tersebut adalah pertama, orientasi manusia yang mengejar rasa "welas asih" dan kepedulian terhadap kehidupan pekerja. Orang-orang yang berasal dari budaya orientasi manusia percaya bahwa welas asih dan kepedulian terhadap pekerja adalah penting di tempat kerja. Bullying di tempat kerja biasanya tidak akan terjadi dengan orang-orang yang berorientasi pada manusia. Kedua, orientasi kinerja, lebih menekankan pada kemampuan untuk bekerja daripada hubungan dengan orang. Biasanya pemilik perusahaan akan memberikan tekanan yang lebih tinggi kepada karyawan dengan dalih agar mereka dapat menyelesaikan pekerjaan secara efektif dan efisien sehingga dapat meningkatkan kinerja pekerjaan. Oleh karena itu, karyawan dapat menerima bullying di tempat kerja selama tujuan mereka tercapai. Ketiga, orientasi masa depan, orientasi ini berfokus pada pandangan jangka panjang di mana kebersamaan dan interaksi dapat meningkatkan hubungan dengan karyawan tanpa memandang ras, usia, atau budaya. Biasanya pemilik perusahaan akan sering memberi penghargaan kepada karyawan jika mereka 
mencapai tujuan dengan memberikan hari libur / cuti, hadiah / reward, atau pertemuan.

Bagaimana dengan Penelitian dan Gerakan Anti Bullying di Indonesia?

Penelitian bullying banyak diteliti namun terbatas pada setting sekolah atau setting remaja, belum ditemukan penelitian bullying yang dilakukan secara mendalam dan komprehensif pada setting kerja. Sejauh pengetahuan peneliti, riset tentang bullying di tempat kerja yang ada di Indonesia saat ini masih berada pada area studi deskriptif dan korelasional dengan mengacu pada teori bullying dari Einarsen dan Leymann. Penelitian korelasional bullying biasanya dikaitkan dengan beberapa variabel yang menjadi anteseden maupun outcome dari bullying. Variabel-variabel tersebut di antaranya adalah komitmen, turnover, burnout, dan trait.

Di sisi lain secara praktis terdapat lembaga di Indonesia yang concern terhadap bullying, namun perhatian terbesarnya pada bullying di sekolah dan siber pada remaja ada dua, yaitu pertama, Yayasan Semai Jiwa Amini (Sejiwa) yang didirikan pada 2004 adalah sebuah organisasi nirlaba yang berupaya mendorong perlindungan anak $\mathrm{di}$ Indonesia, khususnya dalam mencegah dan mengatasi isu-isu kekerasan terhadap anak, baik di dunia nyata maupun di dunia online. (www.sejiwa.org). Kedua, Sudah Dong adalah sebuah gerakan anti bullying Indonesia yang diinisiasi oleh Katyana Wardhana dan sekelompok anak muda. Gerakan ini muncul karena banyaknya terjadi kasus bullying di Indonesia dan belum ada sebuah gerakan yang massif untuk menghentikan bullying (www. sudahdong.com)

\section{Penutup}

Bullying di tempat kerja merupakan salah satu persoalan, baik dalam bidang praktis maupun akademis yang cukup sulit untuk diukur dan dimonitor secara akurat. Salah satu penyebabnya adalah adanya keragaman konsep tentang bullying di tempat kerja, sehingga hal ini akan memungkinkan untuk terjadinya perbedaan interpretasi terhadap hasil penelitian yang ada. Maka dari itu perlu adanya satu definisi yang jelas mengenai bullying di tempat kerja dengan mempertimbangkan aspek-aspek yang memengaruhinya, salah satunya adalah faktor sosial budaya di mana konsep bullying tersebut dikembangkan. Hal ini dikarenakan definisi yang jelas dari bullying di tempat kerja tidak terlepas dari adanya pengaruh budaya, baik budaya makro maupun budaya mikro. Budaya makro meliputi budaya suatu negara di mana organisasi berada. Identifikasi terhadap budaya makro dan mikro ini dapat dilakukan dengan menggunakan pendekatan pengukuran budaya dari Hofstede maupun Globe.

Apabila ditinjau secara menyeluruh tampak bahwa bullying di tempat kerja ini memberikan dampak yang negatif bagi individu, kelompok, organisasi, maupun lingkungan sosial secara luas, maka dari itu diperlukan pendekatan yang terintegrasi dalam menangani persoalan bullying ini.

\section{Daftar Pustaka}

Agarwal, U. A. \& Gupta, R. G. (2016). Examining the nature and effects of psychological contract: Case study of an Indian organization. Thunderbird International Business Review. doi: 10.1002/ tie. 21870 .

Andersson, L. M. \& Pearson, C. M. (1999). Tit for tat? The spiraling effect of incivility in the workplace. Academy of Management Review, 24(4), 52- 71.

Aquino, K., Grover, S. L., Bradfield, M., \& Allen, D. G. (1999). The effects of negative affectivity, hierarchical status. 
Academy of Management, 42(3), 260-272. doi: $10.2307 / 256918$

Bennett, R. J. \& Robinson, S. L. (2003) The past, present and future of workplace deviance research. In J. Greenberg (Ed.), Organizational behavior: The state of the science (2ndedn). Mahwah, NJ: Erlbaum.

Bjorkqvist, K., Osterman, K., \& Hielt-Back, M. (1994). Aggression among university employees. Aggressive Behavior Journal, 20(3), 173-184. doi: 10.10002/1098-2337

Branch, S., Ramsay, S., \& Barker, M. (2013). Workplace bullying, mobbing and general harassment: A review. International Journal of Management Reviews, 15(3), 280-299. doi: 10.1111/j.1468-2370. 2012.00339.x

Brodsky, C. (1976). The harassed worker. Lexington, MA: Lexington Books.

Duffy, M. \& Sperry, L. (2007). Workplace mobbing: Individual and family health consequences. The Family Journal. 15, 398. doi: 10.1177/1066480707305069

Einarsen, S. (1996). Bullying and harassment at work: Epidemiological and psychosocial aspects. Doctoral dissertation, Department of Psychosocial Science, University of Bergen.

Einarsen, S. (2000). Harassment and bullying at work: A review of the Scandinavian approach. Aggression and Violent Behavior, 5(4), 379-401. doi: 10.1016/ S1359-1789(98)00043-3

Einarsen, S., \& Skogstad, A. (1996). Bullying at work: Epidemiological findings in public and private organizations. European Journal of Work and Organizational Psychology, 5(2), 185-201. doi: 10.1080/13594329608414854

Einarsen, S., Hoel, H., Zapf, D., \& Cooper, C. L. (2003). The concept of bullying at work: The european tradition. In S. Einarsen, H. Hoel, D. Zapf \& C. L.
Cooper (Eds.), Bullying and emotional abuse in the workplace: International perspectives in research and practice (pp. 330). New York, NY: Taylor \& Francis.

Einarsen, S., Hoel, H., Zapf, D., \& Cooper, C. L. (2011). The concept of bullying and harassment at work: The European tradition. In S. Einarsen, H. Hoel, D. Zapf \& C. L. Cooper (Eds.), Bullying and harassment in the workplace: Developments in theory, research, and practice (2nd ed.), (pp. 3-39). Boca Raton, FL: CRC Press.

Gunawan, R., Prihanto, S., \& Yuwanto, L. (2009). Causes and the intensity of workplace bullying. Anima, Indonesian Psychology Journal, 25(1), 47-54.

Hidayati, N. \& Rahayuningsih, I. (2014). Bentuk dan dampak kekerasan di tempat kerja (workplace bullying) pada buruh pabrik di gresik. Jurnal Psikosains, 9(2), 125-139.

Hutchinson, M., Wilkes, L., Jackson, D., \& Vickers, M. H. (2010). Integrating individual, work group and organizational factors: Testing a multidimensional model of bullying in the nursing workplace. Journal of Nursing Management, 18(2), 173-181. doi: 10. 1111/ j.1365-2834.2009.01035.x.

Jennifer, M. I. L., Restubog, S. L. D., \& Zagenczyk, T. J. (2010). Consequences of workplace bullying on employee identification and satisfaction among Australians and Singaporeans. Journal of Cross-Cultural Psychology, 41(2), 236-252. doi: 10.1177/0022022109354641

Pusat Bahasa Kementerian Pendidikan Nasional. (2016). Kamus Besar Bahasa Indonesia (KBBI). Jakarta: Balai Pustaka.

Keashly, L., Trott, V. \& MacLean, L. M. (1994). Abusive behavior in the workplace: A preliminary investigation. Violence and Victims, 9(4), 341-357. 
Lewis, D. (2003). Voices in the social construction of bullying at work: Exploring multiple realities in further and higher education. International Journal of Management and Decision Making, 4(1), 65-81.

Leymann, H. (1990). Mobbing and psychological terror at workplaces. Violence and Victims, 5(2), 119-126.

Lutgen-Sandvik, P. (2005). Water smoothing stones: Subordinate resistance to workplace bullying (Doctoral dissertation). Arizona State University, Tempe, AZ. Retrieved from https://www.ndsu.edu/ pubweb/ lutgensa/Resistance $\% 20$ to $\%$ 20Workplace\%20Bullying\%20LutgenSandvik\%20 Dissertation\%202005.pdf

Namie, G. (2003). Workplace bullying: Escalated incivility. Ivey Bussiness Journal. 12, 1-7.

Neuman, J. H. \& Baron, R. A. (1998). Workplace violence and workplace aggression: Evidence concerning specific forms, potential causes, and preferred targets. Journal of Management, 24(3), 391-419. doi: 10.1177/ 014920639802400305

O'Leary-Kelly, A. M., Griffin, R. W. \& Glew, D. J. (1996). Organization-motivated aggression: A research framework. Academy of Manage Review, 21(1), 225253.

Parzefall, M.-R., \& Salin, D. M. (2010). Perceptions of and reactions to workplace bullying: A social exchange perspective. Human Relations, 63(6), 761780. doi: 10.1177/0018726709345043

Power, J. L., Brotheridge, C. M., Blenkinsopp, J., Bowes-Sperry, L., Bozionelos, N., Buzády, Z., Chuang, A., ....\& Madero, S.M., (2013). Acceptability of workplace bullying: A comparative study on six continents.
Journal of Business Research, 66(3), 374380. doi: 10.1016/ j.jbusres. 2011.08.018

Rudi, T. (2010). Informasi perihal bullying. Diperoleh dari https://bigloveadagio. files.wordpress.com/2010/03/informasi_ perihal_bullying.pdf. Diakses pada tanggal 2 Juli 2018.

Salin, D. (2001) Prevalence and forms of bullying among business professionals: A comparison of two different strategies for measuring bullying. European Journal of Work and Organizational Psychology, 10 (4), 425-441. doi: 10.1080/135943201430 00771

Salsabila, I. (2018). Google kewalahan cegah bullying di kantor. Diperoleh dari https://inet.detik.com/cyberlife/d4092933/google-kewalahan-cegahbullying-di-kantor. Diakses pada tanggal 2 Juli 2018.

Samnani, A. K. (2012). 20 Years of workplace bullying research: A review of the antecedents and consequences of bullying in the workplace. Aggression and Violent Behavior. 17(6), 581-589. doi: 10. 1016/j.avb.2012.08.004

Sidle, S. D. (2010). Eye of the beholder: Does culture shape perceptions of workplace bullying? The Academy of Management Perspectives, 24(3), 100-101.

Stouten, J., Baillien, E., Van den Broeck, A., Camps, J., De Witte, H., \& Euwema, M. (2010). Discouraging bullying: The role of ethical leadership and its effects on the work environment. Journal of Business Ethics, 95(1), 17-27.

Thylefors, I. (1987). Syndabockar. (Scapegoats. Exlusion and bullying in worklife). Stockholm: Natur och Kultur.

Timucin, A., Yildirim, A., \& Yildirim, D (2007). Mobbing behaviors encountered by nurse teaching staff. Nurse Ethics, London: Sage Publications. 


\section{BULLYING DI TEMPAT KERJA DI INDONESIA}

Vartia, M. (1996). The sources of bullying: Psychosocial work environment and organizational climate. European Journal of Work and Organizational Psychology 5(2), 203-214. doi: 10.1080/13594329608 414855

Westhues, K. (2003). At the mercy of the mob. Canada's Occupational Health $\mathcal{E}$ Safety Magazine, 18(8), 30-36. Published online at http://arts.uwaterloo.ca/ $\sim$ kwesthue/ohs-canada.htm $>$ January 2003.

Wilson, C. B. (1991). U.S. Businesses suffer from workplace trauma. Personnel Journal, 47-50.

Workplace Bullying Institute. (2017). U.S workplace bullying survey: National prevalence. https://www.workplacebullying.org/wbiresearch/wbi-2017survey/

www.sejiwa.org diakses pada tanggal 2 juli 2018.

www.sudahdong.com diakses pada tanggal 2 juli 2018.

Zapf, D. (1999) Organisational, work group related and personal causes of mobbing/bullying at work. International Journal of Manpower, 20(1/2), 70-85.

Zapf, D. \& Einarsen, S. (2001). Bullying in the workplace: Recent trend in research and practice an introduction. European Journal of Work and Organizational Psychology, 10(4), 369-373. doi: 10.1080/ 13594320143000807 